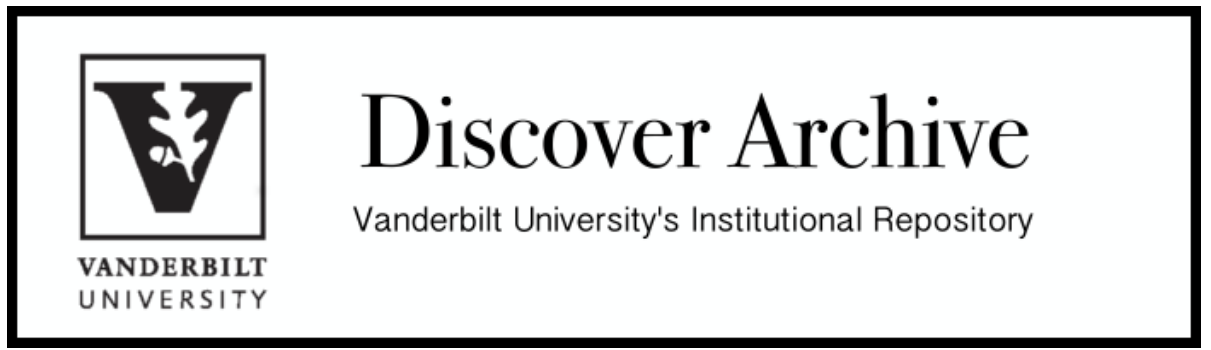

This work was originally published as: Richard Zeckhauser and W. Kip Viscusi, Discounting Dilemmas: Editors' Introduction - 37 Journal of Risk and Uncertainty 95 (2008). 
Discounting Dilemmas: Editors' Introduction

by

Richard Zeckhauser ${ }^{*}$ and W. Kip Viscusi ${ }^{* *}$

September 4, 2008

Corresponding author:

W. Kip Viscusi

University Distinguished Professor of Law, Economics, and Management

Vanderbilt University Law School

$13121^{\text {st }}$ Avenue South

Nashville, TN 37203

p: (615) $343-7715$

f: $(615) 322-5953$

kip.viscusi@ vanderbilt.edu

\footnotetext{
* Kennedy School of Government, Harvard University, Cambridge, MA 02138.

** Vanderbilt University Law School, $13121^{\text {st }}$ Ave. South, Nashville, TN 37203.
} 


\begin{abstract}
Two developments pose dilemmas for well established discounting techniques: (1) The extremely long time horizons associated with recently prominent environmental policy problems, such as climate change and nuclear waste storage, have made it important to take seriously both benefits to future generations and extreme uncertainties in projecting the returns to policies and future well being. (2) Findings in the burgeoning field of behavioral economics have made it clear that individuals routinely depart significantly from rational prescriptions when making choices over time, thus undermining a bulwark of the discounting approach. These two sets of dilemmas are addressed in a series of papers under the headings normative analyses and behavioral analyses. These papers use concepts from psychology and philosophy to complement their economic approach.
\end{abstract}

JEL Classification: C25, D91, Q25

Keywords: Discounting, climate change, risk, irrationality 
Discounting is like subatomic physics, only the math is easier. Just when we have it mastered, new phenomena change our understanding. Moreover, that new understanding often raises deep philosophical problems. This special issue of the Journal of Risk and Uncertainty takes on the intertwined problems of time and uncertainty. It explores discounting dilemmas that arise in two contexts: (1) societal choices that involve extremely long time dimensions, implying substantial uncertainties, and (2) individuals' time-related behaviors, where their natural propensities lead them to deviate substantially from traditional prescriptions. These are respectively the normative and behavioral categories that organize this issue.

In Irving Fisher's day with discounting, like Isaac Newton's day with physics, most was resolved. Getting the discount rate right was no harder than predicting how a ball would roll down an inclined plane or where a tangency might be found between a curve and a line. Individuals and firms would equate their marginal rates of substitution for consumption across time periods to the market rate of interest. Savers and investors would employ the same rates.

Then public finance and welfare economics swung into action, and governments became a major player. Market imperfections got attention, and a profound literature emerged on the social rate of discount. Though the controversy was never completely resolved, it was widely recognized that we live in a second-best world, and that the government could not simply use market rates when making its investment decisions. As the debate swirled, the government finally settled on rates to be employed for various projects. For example, in 2008, the government recommended using discount rates of $3 \%$ and $7 \%$ for analyzing government regulations. ${ }^{1}$ By contrast, corporations were using hurdle rates of $15 \%$ to $20 \%$, the riskless rate of interest was $2 \%$ for 3 -month Treasury bills and $4 \%$ for 10 -year government bonds, and consumers were investing in savings accounts yielding at best $2 \%$, but were borrowing on credit cards on rates near the corporate hurdle rates. In short, Irving Fisher's equilibrium outcome was far from being realized.

The economist's ideal equilibrium relative to discounting was thwarted in another respect: Prescriptions that economists widely accepted were widely ignored by the real world,

\footnotetext{
${ }^{1}$ Office of Management and Budget, Circular A-4, Regulatory Analysis (2003), accessed online at http://www.whitehouse.gov/OMB/Circulars/a004/a-4.pdf.
} 
even in such hard-headed domains as finance. Let us mention two examples. Economists generally agree that whoever is the decision maker, the discount rate should not be adjusted for risk. The preferred approach, roughly speaking, is to address risk by converting monetary payoffs to certainty equivalents, and then do the discounting. To be sure, such calculations become a bit more complicated when there are liquidity constraints along the way, when both consumption and wealth are involved, when decisions along the way can be adjusted in response to intermediate outcomes, etc. But the lesson is clear. Risk is risk, and time preference is time preference. Though risk and time are inevitably entangled as we confront them, they should be separated as best as possible when we analyze them. Despite such understanding, real world decision makers routinely raise their discount rates when confronted with risk. Even on Wall Street, concepts such as certainty equivalents and utility theory may be used by some technicians, but not by the major players.

Perhaps more surprising, the most sophisticated players in finance shun the concept of discounted present value. The language of venture capitalists, real estate developers, and private equity investors revolves around internal rates of return, with the ubiquitous abbreviation IRRs. At times, these practitioners talk about returns in terms of multiples of invested capital. But they virtually never tell you that for someone with a personal discount rate of say $10 \%$, the investment of \$100,000 was worth \$YYY at the outset, when \$YYY is the relevant number. The use of IRR numbers would make sense if someone could continually reinvest at that rate, but that is rarely the case. This hard-to-buck convention makes a difference, and often leads to short-termism and otherwise poor decisions. There can be little doubt, for example, that some private equity managers may sell out an investment in three years to secure a reported IRR of say $25 \%$, when most of their investors would far prefer a $20 \%$ return that persisted over seven years.

In recent years, two phenomena have stepped in to drastically change economists' thinking about discount rates: the behavioral economics revolution and the climate change debate. The first is internal to the profession, the second is well beyond it. Each of these phenomena has had concerns of risk and time in the forefront. Behavioral economists and psychologists have found that many anomalies in individual choice pertain to how people handle the risk and time dimensions of decisions. Similarly, policymakers in the climate change debate 
and other long-term environmental contexts must grapple with tremendous risks, particularly with respect to temporally distant impacts.

Every parent is familiar with myopia or excessive impatience, or what modern economists call hyperbolic or beta-delta discounting. Presumably such impatience was recognized in antiquity, though economists did not get to it until the $19^{\text {th }}$ century, ${ }^{2}$ and did not give it rigorous treatment till near the end of the $20^{\text {th }}$ century. Many other anomalies relating to time preference have emerged, such as a preference for improving consumption streams (sometimes bizarrely coupled with myopia), but none so powerful as the extreme preference for present payoffs. Samuelson, in this issue, provides historical perspective on these developments.

Economists' efforts have expanded well beyond conceptual models of discounting behavior. In recent years, they have conducted innumerable laboratory experiments and surveys to assess the time tradeoffs of individuals. Three papers in the current volume - those by Viscusi, Huber, and Bell; by Frederick and Lowenstein; and by Chabris et al.- represent contributions in this tradition.

Other disciplines are in this time-tradeoff business as well, most notably psychologists. A salient early study by psychologists ${ }^{3}$ anticipated later economic work relating patience to subsequent life success. ${ }^{4}$ Young children who were able to resist eating a marshmallow, or equivalent, for a period in return for a second marshmallow reward did better in their adolescent competencies. Follow-up studies showed that they did better on their SAT scores and in years of higher education secured. Recent work by psychologists on happiness, often working in conjunction with economists, has raised the question whether the economist's discounting

\footnotetext{
${ }^{2}$ See the helpful survey article by Frederick et al. (2002), which provides both a history of discounting and a thorough review of recent literature.

${ }^{3}$ Mischel et al. (1988).

${ }^{4}$ Samuelson (2008) briefly discusses the patience-success relationship. Chabris et al. (2008) relate laboratorymeasured discount rates to 15 field behaviors and indicators, such as smoking, exercise, and body-mass index.
} 
model, whatever rates are employed, misses many fundamental forces. ${ }^{5}$ To illustrate, time spent on an activity may correlate weakly with the pleasure or pain it is reported to cause, a phenomenon called duration neglect, whereas experience at the peak or very end may count heavily. ${ }^{6}$ Reported happiness diverges strongly from sums achieved by applying weighting factors to streams of returns (such as reported subjective well being) over time. The implications of such findings for measuring happiness are not clear. How strongly should we value retrospective reports relative to time diaries, for example? Adding time-delay concerns to the assessment would only make the question harder. ${ }^{7}$

Very recent studies using fMRI scans (McClure et al. 2004) have shown that anticipated immediate and future rewards show up in different locations in the brain, which starts to explain the divergence between observed actions and economists' normative models. But even a full explanation would merely stir additional debate on the established question as to whether people should respond as their brains incline or as economists prescribe.

Behavioral economics and climate change, our principal environmental case study, are strange bedfellows. Behavioral economics, working from inside the profession, has raised the importance for discounting theory and practice of how individuals actually behave. Climatechange concerns have raised the importance of the question of how societies ought to behave. Behavioral economics suggests that (or at least explains why) individuals should be free to

\footnotetext{
${ }^{5}$ Psychologists have also chronicled a variety of systematic mistakes in the way humans contemplate the future. For example, individuals make the effective forecasting error that "hedonic states will be less intense in the future than in the present," which obviously leads to strong present orientation. See Kassam et al. (in press).

${ }^{6}$ Redelmeier (a physician) and Kahneman (1996) showed this in a well known experiment using colonoscopies. Leaving the probe in gently at the end, producing an increment of discomfort, yielded a less negative recollected experience. Kahneman (1997) and colleagues distinguish among decision utility, experienced utility, and remembered utility. They go on (p. 375) to "propose a formal normative theory of the total experienced utility of temporally extended outcomes." Their treatment suggests that economists had banished experienced utility in favor of decision utility. However, we view their proposal as consistent with the stream of period or continuous utilities framework that populates so many contemporary economic models. They are not full fellow travelers; their proposal favors time neutrality over discounting.

${ }^{7}$ See the ambitious proposal by Krueger et al. (2007) to measure well being through what they label a National Time Accounting approach. It attempts to measure a society's subjective well-being, based on time allocation and affective experience.
} 
march to their own time beat, a beat much faster than the normal economics tempo, at least in the short run. Reflections on climate-change concerns, by contrast, have led a number of economists, including a few contributing to this volume, to consider applying much lower discount rates to long-term problems than economists normally employ.

\section{Normative analyses}

Many of the most important societal problems will play out over extremely long time horizons. What happens tomorrow is uncertain. What happens over 15,000 tomorrows is massively uncertain, and so it is with climate change, the dangers of killer asteroids, and year 2050 energy sources and cancer cures. The normative analyses presented in this issue, which in some cases are informed by behavioral studies, include contributions by Samuelson, Summers and Zeckhauser, Dasgupta, Gollier, and Fels and Zeckhauser. These articles develop the general economic principles for discounting, particularly when there are risks to distant generations.

The central role of the discount rate in environmental policy assessments is well illustrated by simple calculations of the value of $\$ 1$ in benefits in 50 years and in 100 years. With a time discount rate of $3 \%$, which is consistent with the lower value in OMB guidelines and calculations of climate change effects by economists such as Nordhaus (1994), the present value of $\$ 1$ equals $\$ 0.23$ in 50 years, and $\$ 0.05$ in 100 years. The alternative OMB discount rate of $7 \%$ leads to a present value of $\$ 1$ equal to $\$ 0.03$ after 50 years and $\$ 0.001$ in 100 years. The famed Stern Report (2006) on climate change utilized a time discount rate of $0.1 \%$ for tallying benefits, which is close to not discounting at all, and is a low outlier in the debate. ${ }^{8}$ Using that rate, the present value of $\$ 1$ in benefits is $\$ 0.95$ if they are received in 50 years and $\$ 0.90$ if they are received in 100 years. Stern's positive, albeit miniscule, rate comes not from time preference, nor because we value future generations less than our own. Such preferences he finds ethically indefensible, and draws support from Ramsey, Pigou and later distinguished writers. Rather, it allows for the possibility that human life may not exist in the future, perhaps smitten by a meteorite (Stern (2007), pp. 35-37, 53).

\footnotetext{
${ }^{8}$ The climate change analysis by Stern (2007) is the subject of detailed commentaries by Nordhaus (2007) and Weitzman (2007).
} 
If we exclude discount rates for benefits such as $7 \%$ as being too high, which most economists believe is the case, then the main intellectual battleground is whether we should be using discount rates in the range of $3 \%$ or discounting by only a token nonzero amount, such as $0.1 \%$.

The potentially dominant role of discounting in long-term policy analyses, in conjunction with the embodied substantial uncertainties, is strikingly illustrated in the U.S. Environmental Protection Agency's (EPA) analysis of nuclear waste storage at Yucca Mountain, a site about 100 miles northwest of Las Vegas, Nevada. ${ }^{9}$ EPA initially prepared a regulatory analysis providing for the sufficient safety of the nuclear waste storage for 10,000 years, but in response to a Federal court decision it extended the period for analysis demonstrating safe storage to 1 million years. To put these time frames in perspective, recorded human history spans only 5,000 years, and homo sapiens have walked the earth for a mere 120,000 years. Even at the more immediate 10,000 year time period, a $\$ 1$ benefit valued at a 3\% discount rate would have a present value of only $\$ 4.2 \times 10^{-129}$. The present economic value of exposing the entire current U.S. population to a lethal dose of radiation in 10,000 years is so small that it would drop out of the analysis at any reasonable discount rate. Perhaps because discounting would obliterate the value of such remote benefits, EPA didn't provide a present value calculation of the 1 million years of secure storage.

The EPA analysis assures us that the nuclear waste stored underground at Yucca Mountain will expose nobody in the next 10,000 years to a radiation level of over 15 millirems of radiation. Even more striking is its assurance that nobody in the next million years will be exposed to more than 350 millirems. That is half the average background radiation risk currently faced by Colorado residents. EPA avoided the question, which a skeptical economist might pose, of what probabilities should be attached to such terms as "nobody" and "secure" when applied to million-year periods. As we move from 100 years to 10,000 years, the crystal ball for safety goes from cloudy to pitch black. And million year projections surely transform regulatory

\footnotetext{
${ }^{9}$ U.S. Environmental Protection Agency, Public Health and Environmental Radiation Protection Standards for Yucca Mountain, NV, 70 Federal Register 49014 (2005). For a detailed critique of the EPA analysis, see Viscusi (2007).
} 
impact analyses from bureaucratic documents into science fiction fantasies. The articles in this issue stop well short of fantasia; they reside in plausibilia. Thus, they address time frames going from days to decades and from decades to centuries, but never get close to millennia.

Challenges raised by greenhouse gas emissions are the prime policy issue addressed in these papers. Many policy problems have long-term consequences, but few have crystallized intellectual examination of the far future, particularly by economists, as strongly as has the potential for climate change. It is quite possible that actions taken today, notably the emission of greenhouse gases, will have significant consequences on people living 100 or 200 years hence. Here you will find Summers and Zeckhauser (2008), drawing on both psychological and philosophical principles, who suggest that the weights put on the welfares of far future generations should be much closer to those of nearby generations than any traditional discounting formulation would produce. Gollier (2008), employing a neoclassical model, shows how appropriate concern for the distribution and persistence of future growth rates will lead to a systematic decline in discount rates as the future stretches forward. Fels and Zeckhauser (2008) put a philosophical nail in the constant-discount-rate coffin. They show that perfect altruism (treating all pairs of successive generations alike) is inconsistent with total altruism (valuing other generations' altruistic preferences, not merely their felicities from consumption). These three papers, and most notably that of Dasgupta (2008), should be viewed alongside the Stern Report. Dasgupta reviews the climate change discount rate controversy the Stern Report raised, and then wades into the subsequent swirl of economic debate.

We now review our normative papers in more detail. Samuelson conducts an historical tour of discounting concepts. He observes that behavior that shortchanges savings and other excessively impatient or Pollyannish actions had been observed, bemoaned and exploited eons before credit cards entered our wallets or myopia the economist's vocabulary. He observes that patience and prosperity will be bed partners, as will their opposites, and then generalizes the lesson, identifying shortsighted choices in areas ranging from sex to smoking. He then derides laws against usury, taking kings, the Old Testament, a couple of religions, and Karl Marx to task. Chicago economics gets poked along the way. Samuelson-capitalizing on his multiple-decade 
perspective - closes by identifying optimal life-cycle investing strategy: keep steady allocations as you go.

Summers and Zeckhauser take on the problem of policymaking for the long-term future, what they label posterity. They employ a variety of paradigmatic choice problems to illustrate the problems and insights into methods for valuing future consequences. Thus, they ask such questions as: (1) If given a choice would you destroy a threatening comet to return in 100 years, or one in 300 years, if the latter represented a 10 times greater threat? (2) Why do you treat dropping litter so differently from failing to pick it up? (3) What fraction of your income would you give up to avoid a $1 \%$ chance of a cataclysm that would kill you as it made the human species extinct? (4) If your predecessors set a noble precedent by saving more for you, will you follow it, hoping that strengthens the precedent for your descendants, or would you free ride by consuming some of your inheritance? They use such questions, traditional economics and behavioral economics to address policymaking for posterity, first for a certain world and then for an uncertain world. The example of actions against climate change suffuses their discussion. Under certainty, they find a case for giving more weight to the distant future, taking more actions on its behalf, than would be implied by choosing "reasonable" parameters for the fundamental discounting equation. Their conclusions from the uncertainty analysis push in opposite directions from conventional wisdom, primarily because they find that in a von NeumannMorgenstern framework logic does not support assigning infinite negative value to even the extinction of human life. Their model of uncertainty and learning, developed for the climate change example, shows that greater uncertainty may increase or decrease the optimal percentage of total expected mitigation undertaken in the first period. Summers and Zeckhauser close with a discussion of reaction function issues. That is, they assess how current efforts to help the future, say to curb greenhouse gas emissions, will affect alternative investments of benefit to the future, actions by other generations and other nations, and technological developments.

Dasgupta develops a model of how time preference and societal preferences for income distribution across time should influence the valuation of such deferred policy impacts. His framework is driven by key ethical assumptions, relating in particular to intergenerational inequality in consumption. In Dasgupta's model, the consumption discount rate, which 
determines the weights placed on consumption levels at different times, plays a key role. In any year $t$, it is the sum of the time discount rate and a term that is the product of the predicted growth in consumption from year $t$ to $t+1$ and the elasticity of what he calls marginal felicity, i.e., instantaneous marginal utility of consumption. Dasgupta favors a time discount rate of approximately zero, which accords better with the Stern Report's $0.1 \%$ value than the U.S. government-recommended time discount rates. However, Dasgupta departs from the Stern Report approach in that he favors a higher value of the elasticity of marginal felicity than used in past climate change studies. Therefore, he would place a very high social weight on avoiding the risk of inequality of consumption levels for future generations. Dasgupta's belief that there should be a very strong concern with possible future inequality seems initially inconsistent with the current generation's willingness to tolerate substantial current income inequality across nations. However, he discusses this observation and suggests that our willingness to reduce inequality for future generations should be greater than our apparent willingness to fund efforts to eliminate dire poverty, say in African countries. His elegant formulation requires economists to concern themselves not merely with estimating the highly uncertain climate change effects, but also with the temporal trajectory of income inequality, a theme echoed by the next article.

Gollier follows the classic discounting approach, which posits that a dollar today is worth more than a dollar tomorrow, because the marginal utility of consumption is decreasing when consumption grows over time. If consumption growth follows a Markov process, everything is copasetic: constant discounting does an excellent job given an appropriate CRRA utility function. Gollier observes that prosperity may be just around the corner, and many corners after that. But history is also filled with long slumps and slowdowns, often associated with afflictions such as wars and plagues. He then develops the theory of appropriate discounting when there are future uncertain shocks to growth. With only this slight but realistic departure from standard assumptions, Gollier is able to show that as time stretches forward the discount rates we should apply at present will drop. Basically, that is due to an asymmetry between the effects of high and low growth rates. Call the average long-term growth rate middle. Looking to the far distance, an uptick in growth rates will matter little; a dollar will be worth virtually nothing with either rate. But if the growth rate oozes to low over a long period, and sticks there, a future dollar will gain significant value, in part because of risk aversion and disappointing consumption. Gollier 
divides discount rates into two components, a wealth effect and a precautionary effect. The latter protects against low growth rates. Alternative specifications have proper discount rates falling from $4.3 \%$ to $3.4 \%$ over 100 years, and from $3.5 \%$ to $1 \%$ over a millennium.

Fels and Zeckhauser take altruism seriously. They posit that generations, or for that matter altruistic individuals, should respect the preferences of those for whom they have altruism. Thus, if those generations are altruistic, their full utility function should be considered, not just the felicity they get from own consumption. They show that this concept, total altruism, can yield a functional form that depends only on each generation's felicity of consumption. They show, however, that what has been labeled perfect altruism, namely that a generation value itself relative to a successor the way it values any two successive generations, is incompatible with total altruism. They close with a philosophical pitch for having altruism stretch backward as well as forward, and claim that the real world at times respects such backward looking preferences.

\section{Behavioral analyses}

The three behavioral papers presented here explore issues pertaining to discounting and risks over time for situations quite apart from climate change, and generally much shorter term. These papers flow in the spirit of the behavioral economics literature, which has identified a variety of systematic anomalies in how people make choices involving critical time dimensions. The papers utilize a broad range of approaches and address several different topics. Viscusi, Huber, and Bell use a national survey to elicit people's stated preferences with respect to a series of hypothetical environmental policy choices. Their approach consequently addresses behavioral issues but adopts a methodology more common within the environmental stated preference literature. Their results provide an empirical basis for estimating individual utility functions for policy costs and for environmental quality at different points in time. The Frederick and Loewenstein article utilizes the more familiar approach in the behavioral economics literature, namely relying on a variety of convenience samples, ranging from members of a jury pool to various student groups. The sample members respond to a series of hypothetical choice decisions. The novelty of the study is their analysis of whether the trajectory over time in the pattern of these choices fundamentally affects the choices that people make. The final 
behavioral paper by Chabris et al. uses convenience samples of respondents drawn from the local population, complemented by a Web sample, with special emphasis on recruiting people with particular risk-related characteristics such as being significantly overweight. Their paper combines an analysis of behavioral responses to a series of hypothetical choices to explore whether revealed behavioral anomalies with strong intertemporal implications are strongly predictive of behaviors such as smoking.

Turning to the three behavioral papers in greater detail, Viscusi, Huber, and Bell (2008) utilize a choice-based conjoint approach to consider how people value improvements in the water quality of lakes and rivers. These improvements would begin either immediately, or after a delay of 2 to 6 years. The structure of the stated preference survey makes it possible to estimate utility functions for policy costs and water quality improvements at different points in time. Those who have visited lakes and rivers for recreational purposes in the past year have higher willingness-to-pay values for water quality improvements than those who did not, not surprisingly. What is striking is that they also have lower rates of time preference for improvements throughout the time frames considered. Based on these results we hypothesize that environmentalists may be more forward looking. While there is some evidence of hyperbolic discounting at play for those who visited lakes and rivers, that factor is dwarfed by the $20 \%$ discount rate of those who made no visits, which are two to three times the visitors' discount rates. For non-visitors, the valuation of deferred environmental effects takes two blows: low initial valuation and a high discount rate.

A key component of climate change policies and other environmental efforts with an important temporal dimension is that what is at stake is not environmental quality at a point in time but rather an entire trajectory of quality outcomes. Advocates of aggressive forms of intervention generally paint a bleak picture of a steady deterioration in the livability of the planet. How people react to such trajectories is the focus of the article by Frederick and Loewenstein (2008). When allocating a fixed pattern of positively valued payoffs over time, a trajectory in which the values are front-loaded should be preferred because of pure time preference, the opportunity costs associated with delay, and uncertainty regarding whether deferred rewards will ever be paid. However, some studies have suggested that people favor upward sloping 
trajectories for a variety of reasons: greater anticipatory utility, the contrast between the higher future rewards and lower levels that one has become accustomed to, and the belief that one can extrapolate the positive trend into the future. Frederick and Loewenstein analyze these preferences for sequences using both an allocation procedure in which a discrete choice is made among the available options as well as a pricing procedure in which willingness-to-pay amounts are elicited. A typical choice context is the following. Suppose that you prefer to dine at a fancy French restaurant rather than the local Greek restaurant. Would you rather eat French fancy this month and Greek local next, or vice versa? For what price would you be willing to switch your choice? While the authors conclude that framing and contextual effects are consequential, they do not find evidence to support previous studies' results that people favor improving sequences.

Chabris et al. seek to unite the behavioral experimental literature on discounting and the empirical literature on risky behaviors that have an important time dimension. First, they administered a series of delay discounting task questions from which it is possible to infer the individual's rate of time preference. They then linked the individual's estimated discounting variable to risky behaviors in three different samples: a sample of people with risks associated with being overweight, a sample focusing on cognitive and decision making abilities, and a Web sample for which they considered a wide variety of risky behaviors. These diverse risks included health risks such as BMI, exercise, dental checkups, and smoking, as well as financial risks such as gambling. The authors find the expected correlations: impatient people have worse risk profiles, thus reinforcing Samuelson's observations. However, the simple correlations of discount rates with these risky behaviors are 0.09 to 0.38 , which the authors view as low. The strength of the effects makes it clear that factors beyond discounting, such as heterogeneity in individual tastes and geographic variation in cigarette taxes, help to drive these present-oriented behaviors. The authors provide a theoretical model that explains why their findings are as strong as could be expected.

\section{Conclusion}

Discounting has become much more than a mere one-parameter exponential formula in economics. It now spills over into philosophy and psychology, and assumes different forms depending on who is applying it and to what purpose. Its appropriate use has become a subject 
of intense debate wherever time-related choices must be made. In short, discounting is a concept worthy of this journal volume on the dilemmas it raises.

The time-related choices in this issue can be classified on two prime dimensions. First, is a society or an individual making the decision? Second, is the decision being prescribed or described, is it normative or behavioral? In essence, this places discounting problems in a $2 \times 2$ matrix, with most discussion on the diagonal, namely in the societal-normative box or the individual-behavioral box. A great challenge is how and whether to cross between boxes. If society is making the decision, of what normative value are the choices that individuals would make — with or without guidance — on those issues? If we are prescribing for individuals, say in determining how much they should save, what guidance if any should we take from their behavioral proclivities? And should the answer to that question depend on how long it will take for the outcome to be resolved, or whether their deviation from rational prescription relates mainly to time issues or to those of uncertainty?

Our policy discussions have focused on issues that span decades, perhaps centuries. This raises new classes of behavioral concerns. Getting the discount rate for the initial period wrong, the affliction brought on by hyperbolic discounting, would seem to be much less consequential in such contexts than getting the sequence of discount rates for the next dozens of periods right. But even moderate hyperbolic preferences might postpone critical action against a long-term serious problem, and doubly so with generational selfishness. Even when consequences stretch to posterity, both initial period and long-term rates are consequential.

Long-term problems highlight other forms of irrationality, particularly those surrounding issues of uncertainty. A frequently observed failure is that people do not recognize all pertinent states of the world; they have poor peripheral vision for unlikely possibilities. The extreme case is that of ignorance - situations where the states of the world are not identified - when unlikely possibilities are slighted or not even recognized. ${ }^{10}$ Individuals might be excused in this respect,

\footnotetext{
${ }^{10}$ On ignorance, see Zeckhauser (2006), who shows that individuals tend to discount unspecified possibilities. When the Exxon Valdez tanker ran aground at Bligh Reef, causing the nation's biggest oil spill, the possibility that the ship captain would be drunk and would leave the bridge even though regulations required his presence until after the ship left Prince William Sound was not on Exxon's roster of potential disasters. Howard Raiffa likes to recount his lecture on fault trees at the National Academy of Sciences to illustrate the difficulty of identifying relevant states.
} 
but surely government assessments should held to a higher standard. Alas, regulatory policy assessments for environmental regulations often fail to recognize that there even is a long-term impact that should be taken into account. Remarkably, not a single major U.S. regulation in 2004 included an analysis of the effects of the regulation on future generations. ${ }^{11}$ The simplest way to avoid discounting errors in the treatment of the far future is simply not to see the future at all. When long time periods and uncertainty impede ordinary vision, as the papers in this volume demonstrate, economics can serve as both searchlight and spectacles.

He employed the example of why a car wouldn't start. After his presentation, he walked with colleagues to his car, and it failed to start. It was the wrong car, an event not appearing on his fault tree. A closely related hypothesis is that relating to support theory. See Tversky and Koehler (1994) and Idson et al. (2001).

${ }^{11}$ See the U.S. Office of Management and Budget, Draft 2005 Report to Congress on the Costs and Benefits of Regulation. 


\section{References}

Chabris, Christopher F., David Laibson, Carrie L. Morris, Jonathon P. Schuldt, and Dmitry Taubinsky. "Individual Laboratory-Measured Discount Rates Predict Field Behavior," Journal of Risk and Uncertainty 37(2/3), current issue.

Dasgupta, Partha. (2008). "Discounting Climate Change," Journal of Risk and Uncertainty $37(2 / 3)$, current issue.

Fels, Stephen and Richard Zeckhauser. (2008). "Perfect and Total Altruism Across the Generations," Journal of Risk and Uncertainty 37(2/3), current issue.

Frederick, Shane and George Loewenstein. (2008). "Conflicting Motives in Evaluations of Sequences," Journal of Risk and Uncertainty 37(2/3), current issue.

Frederick, S., Loewenstein, G., and O'Donoghue, T. (2002). "Time Discounting and Time Preference: A Critical Review," Journal of Economic Literature 40, 351-401.

Gollier, Christian. (2008). "Discounting with Fat-Tailed Economic Growth," Journal of Risk and Uncertainty 37(2/3), current issue.

Idson, Lorraine Chen, David H. Krantz, Nicolao Bonini, and Daniel Osherson. (2001). "The Relation between Probability and Evidence Judgment: An Extension of Support Theory," Journal of Risk and Uncertainty 22(3), 227-249.

Kahneman, Daniel, Peter P. Wakker, and Rakesh Sarin. (1997). "Back to Bentham: Explorations of Experienced Utility," The Quarterly Journal of Economics 112(2), 375-405.

Kassam, Karim S., Daniel T. Gilbert, Andrew Boston, and Timothy Wilson. (2008). "Future Anhedonia and Time Discounting," Journal of Experimental Social Psychology (in press).

Krueger, Alan B., Daniel Kahneman, David Schkade, Norbert Schwarz, and Arthur A. Stone. (2007). "National Time Accounting: The Currency of Life," NBER Working Paper c5053, http://www.nber.org/chapters/c5053.pdf . 
McClure, Samuel M., David Laibson, George Loewenstein, and Jonathan D. Cohen. (2004). “Separate Neural Systems Value Immediate and Delayed Monetary Rewards," Science 306, Oct. 15, 503-507.

Mischel, Walter, Yuichi Shoda, and Phillip Peake. (1988). “The Nature of Adolescent Competencies Predicted by Preschool Delay of Gratification," Journal of Personality and Social Psychology 54(4), 687-96.

Nordhaus, William D. (1994). Managing the Global Commons: The Economics of Climate Change. Cambridge, MA: MIT Press.

Nordhaus, William D. (2007). “The Stern Review on the Economics of Climate Change,” Journal of Economic Literature 45(3), 686-702.

Redelmeier, David, and Daniel Kahneman. (1996). "Patients' Memories of Painful Medical Treatments: Real-time and Retrospective Evaluations of Two Minimally Invasive Procedures," Pain 66, 3-8.

Samuelson, Paul A. (2008). “Asymmetric or Symmetric Time Preference and Discounting in Many Facets of Economic Theory: A Miscellany," Journal of Risk and Uncertainty $37(2 / 3)$, current issue.

Stern, Nicholas H. et al. (2007). The Economics of Climate Change: The Stern Review. Cambridge: Cambridge University Press.

Summers, Lawrence and Richard Zeckhauser. (2008). "Policymaking for Posterity," Journal of Risk and Uncertainty 37(2/3), current issue.

Tversky, Amos and Derek J. Koehler. (1994). "Support Theory: A Nonextensional Representation of Subjective Probability," Psychological Review 101, 547-567.

Viscusi, W. Kip. (2007). "Rational Discounting for Regulatory Analysis," University of Chicago Law Review 74(1), 209-246. 
Viscusi, W. Kip, Joel Huber, and Jason Bell. (2008). "Estimating Discount Rates for Environmental Quality from Utility-Based Choice Experiments," Journal of Risk and Uncertainty 37(2/3), current issue.

Weitzman, Martin L. (2007). “The Stern Review of the Economics of Climate Change," Journal of Economic Literature 45(3), 703-724.

Zeckhauser, Richard. (2006). "Investing in the Unknown and Unknowable," Capitalism and Society 1(2), Berkeley Electronic Press, http://www.bepress.com/cas/vol1/iss2/art5. 